\title{
Direct Metal Laser Sintering of stainless steel alloy: microstructure and mechanical properties
}

\author{
Genrik Mordas $^{1}$, Ada Steponavičiūtè ${ }^{2}$, Aušra Selskiené ${ }^{3}$, \\ Jurijus Tretjakovas ${ }^{4}$, Sergejus Borodinas ${ }^{5}$ \\ 1, 2, ${ }^{3}$ Center for Physical Sciences and Technology, Vilnius, Lithuania \\ ${ }^{4,5}$ Vilnius Gediminas Technical University, Vilnius, Lithuania \\ E-mail: "Igenrik.mordas@ftmc.lt (corresponding author)
}

\begin{abstract}
Additive manufacturing (AM) is a type of manufacturing technologies whereby the material is added a layer upon layer to produce a 3D object. Produced 3D parts are applied in such industry sectors as space, aviation, automotive, building and has excellent future promises. Ourdays, the commercialy promised technique for metal manufacturing is Direct Metal Laser Sintering (DMLS). Our study concentrated on the investigation of the mechanical properties of produced17-4H (stainless steel) parts using DMLS. The effect of the DMLS process parameters (laser power, scanning speed and energy density) on the ultimate strength, yield strength and Young's modulus was determined. We showed an evolution of the microstructure. The detected defects were classified. This study allowed to determine the optimal regimes of DMLS for SS $17-4 \mathrm{H}$ and describe mechanical properties of the produced parts as well as helped to show future possibilities of DMLS development.
\end{abstract}

Keywords: 3D, DMLS, strength, microstructure, stainless steel.

\section{Introduction}

Additive manufacturing (AM) refers to a group of technologies that fabricate an object layer-by-layer from a threedimensional (3D) Computer Aided Design (CAD) model. New AM technologies, such as Direct Metal Laser Sintering (DMLS), allow producing high-quality metal tools and prototypes of extremely complex geometries. DMLS has significant advantages such as extremely complex geometries, rapid manufacturing with integrated CAD technique, low energy consumption and high level of raw material utilization compared to conventional manufacturing technologies (Viramgama \& Karia, 2016; Abe, Osakada, Shiomi, Uematsu, \& Matsumoto, 2001). The application of the DMLS technology in different industry sectors is strongly dependent on the performance and characteristics of fabricated parts. Therefore, microstructure and mechanical property characterization (Viramgama \& Karia, 2016) with consequent DMLS process optimization helps to overcome the weaknesses and extend its area of use.

In the present paper the attention will be addressed to expose an effect of the laser energy, the laser scanning speed and the energy density on the microstructure and mechanical properties of manufactured parts. As a sample, we use LPW GP1 metal powder.Our research work consists of a study of powder morphology and particle chemical composition, sample fabrication at different DMLS parameters, an investigation of their microstructure and determination of the elastic modulus, tensile strength at elongation and at break. The goal was to find a combination of the optimal DMLS parameter values which allow to produce parts with the smallest number of defects and the largest ultimate tensile strengh.

\section{LPW GP1 metal powder}

The powder examined in this paper was LPW GP1 (trade mark) - a martensitic precipitation strengthened stainless steel 17-4 PH alloy powder, produced by LPW Technology Ltd. Stainless steel 17-4 PH alloy matches high strength, good mechanical properties and good corrosion resistance up to $300^{\circ} \mathrm{C}$. Also, this alloy is the most common member of the class and is generally considered to have the best weldability (LPW GP1 specifications, 2017). However, this powder application in additive technologies still has many questions. 
We perferomed a study of the LPW GP1 powder morphology using scanning electron microscopy (SEM).Used SEM has a dual beam system Helios NanoLab 650 (FEI Company) with energy dispersion X-ray spectrometer INCAEnergy (Oxford Instruments). The system is supplied with a Schottky type field emission electron source and focused Ga ions source. The element mappings were carried out under accelerating voltage of $8 \mathrm{kV}$, beam current of $3.2 \mathrm{nA}$. The powder particles were deposited on the metal film and then analysed (LPW GP1 specifications, 2017).

High-resolution images of the metal particle collection of LPW GP1 powder are presented in Figure 1. The selected scale bar represents 200, 100, 50 and $10 \mu \mathrm{m}$. The images showed that powder has a polydisperse particle size distribution from 10 to $50 \mu \mathrm{m}$. Probably, the maximum size of $50 \mu \mathrm{m}$ is limited due to the powder production process when particles were collected and brushed through a sieve. The size of the smallest particles is determined by the diameter of the atomiser jet nozzle applied for metal powder production (Samal \& Newkirk, 2015). It should be noted that most of the particles seem quite spherical, non-spherical particles caused by smaller spherical particles being attached to larger spherical particles and sticking in.
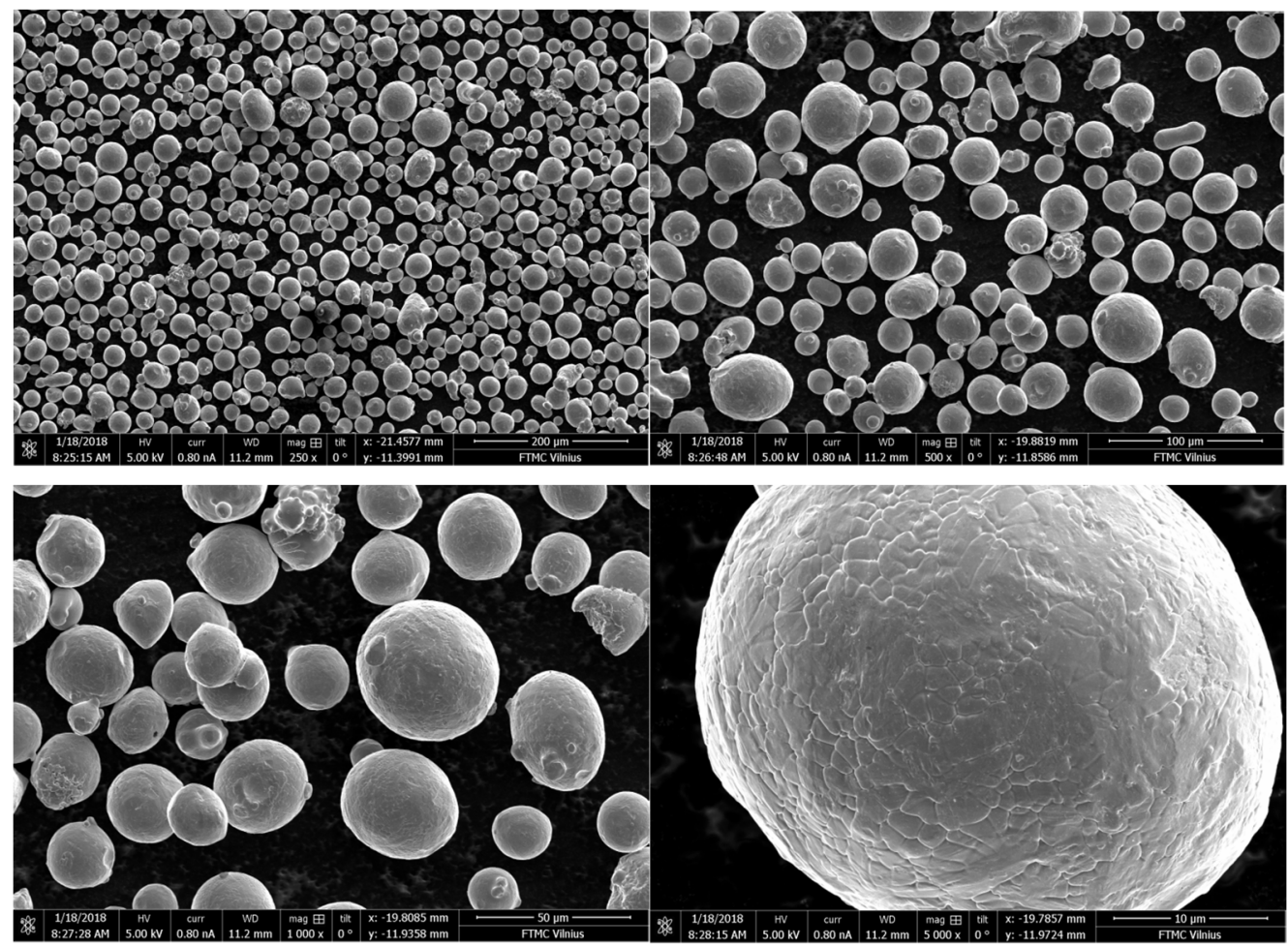

Figure 1. SEM images of LPW GP1 powder using 200, 100, 50 and 10 um scales

Chemical composition of powder provided by the manufacturer LPW Technology Ltd is listed as the default chemical composition [16] (at.\%) in Table 1. According to the manufacturer, the LPW GP1 powder consists of 69.5-78.8 at.\% Fe, 15.0-17.0 at.\% Cr, 3.0-5.0 at.\% Ni, 3.0-5.0 at.\% Cu. SEM-EDS analysis provides average chemical composition results of 10 particles. They show element amounts in the same range as the default estimated chemical composition, with 73.8 at.\% of $\mathrm{Fe}, 16.0$ at.\% of $\mathrm{Cr}, 4.6$ at.\% Ni, 4.2 at.\% $\mathrm{Cu}, 0.77$ at.\% $\mathrm{Si}$ and 0.65 at.\% of $\mathrm{Mn}$ in SEM-EDS results.

Table 1. Chemical composition (at.\%) of the LPW GP1 powder

\begin{tabular}{|l|c|c|c|c|c|c|c|c|c|c|c|}
\hline Element & $\mathbf{F e}$ & $\mathbf{C r}$ & $\mathbf{N i}$ & $\mathbf{C u}$ & $\mathbf{M n}$ & $\mathbf{S i}$ & $\mathbf{M o}$ & $\mathbf{N b}+\mathbf{T a}$ & $\mathbf{C}$ & $\mathbf{P}$ & $\mathbf{S}$ \\
\hline default & balance & $15.0-17.0$ & $3.0-5.0$ & $3.0-5.0$ & $<1.0$ & $<1.0$ & $<1.0$ & $0.2-0.5$ & $<0.1$ & $<0.040$ & $<0.030$ \\
\hline SEM-EDS & 73.8 & 16 & 4.6 & 4.2 & 0.65 & 0.77 & - & - & - & - & - \\
\hline
\end{tabular}

\section{EOSINT M280 and specimen manufacturing}

The DMLS technology is applied in a commercial mashine EOSINT M280 (EOS GmbH-Electro Optical Systems, Krailling, Germany) presented in Figure 2. Also, Figure 2 illustrates the mashine working principle. It can be described in following sequence:

1. 3D object drawing with CAD technique and conversion to STL format;

2. Using the EOSINT M280 software the STL model is sliced into horizontal layers of 20 or $40 \mu \mathrm{m}$; 
3. A layer of metal powder is spread on the top of the building platform;

4. Laser beam traces the geometry of the generated slice and selectively melts and fuses the powder;

5. The building platform with the fused layer is lowered a new layer of powder is spread;

6. The process is repeated until the object is fully fabricated;

7. Finally, the part is removed from the machine and the unsintered powder is sieved back to the powder dispenser for reuse (Pham \& Dimov, 2001; EOS GmbH, 2001; Hanninen, 2002; Abe et al., 2001).

EOSINT M280 has a $200 \mathrm{~W}$ of $1030 \mathrm{~nm}$ built-inYb fibre laser and a high-speed scanner comprising precision galvanometer $(11 \mu \mathrm{rad})$ with temperature compensation. The F-theta objective focuses a laser beam at a building area in $100 \mu \mathrm{m}$. Therein, the powder layer thickness is $20 \mu \mathrm{m}$. The manufacturing process takes place in inert nitrogen atmosphere. The processing chamber of the machine has a working platform of $250 \times 250 \mathrm{~mm}$ and maximum building height up to $325 \mathrm{~mm}$. The building platform is preheated to the temperature of $76{ }^{\circ} \mathrm{C}$. In this study, specimen manufacturing was done using different DMLS parameters. So, the laser power was changed from 70 to $195 \mathrm{~W}$ and scanning speed from 200 to $1000 \mathrm{~mm} / \mathrm{s}$.
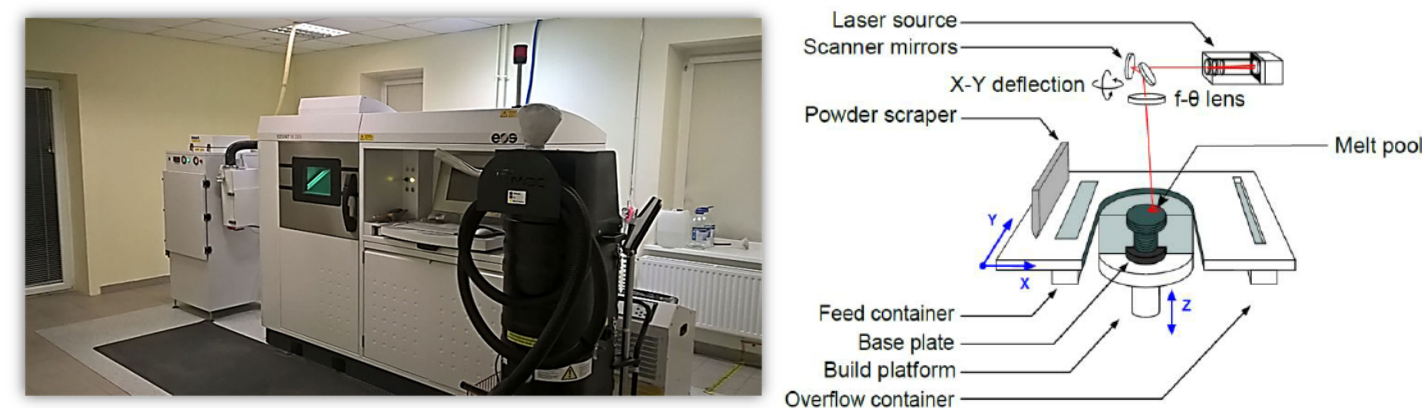

Figure 2. EOSINT M280 machine (in left) and it's principle scheme (in right)

The specimens were built directly on the base plate with $2 \mathrm{~mm}$ soft support, in horizontal orientation having $85 \mathrm{deg}$ angle with powder scraper moving direction. Specimens were two types: a) square of $20 \times 20 \mathrm{~mm}$ and $10 \mathrm{~mm}$ height; b) plate designed with with $3 \mathrm{~mm}$ of width and height, and $35 \mathrm{~mm}$ of length (Figure 3). First type was used for microstructure studies. Second - for investigation of the mechanical properties. Selected dimensions were a compromise between Standard consistency and manufacturing costs. After the building process, the specimens were taken out from the process chamber, cleaned from excessive powder by vacuum cleaner and $2 \mathrm{~mm}$ support was removed. Produced specimens were age-hardened by heating in an oven. The temperature was increased from room temperature to $490{ }^{\circ} \mathrm{C}$ in $1 \mathrm{~h}$; afterwards, they were kept at constant temperature for additional $5 \mathrm{~h}$, before gradual cooling in fresh air. This heat treatment is usually recommended to achieve a reduction of the process-induced tensile residual stresses, with a potential beneficial effect on the tensile response of the built parts (Sanz \& Navas, 2013; Aboulkhair, Maskery, Tuck, Ashcroft, \& Everitt, 2016). Then, a vertical cross-section cut was made on the square type specimens, they were polished with Tegramin-25 (Stuers, Denmark) and analyzed with the optical microscope OLYMPUS BX51TF (Olympus, Germany). The TIRA Test 2300 (with Real - Time PowerPC controller based on $800 \mathrm{MHz}$ CompactRIO) tested tensile stregth of the plate type specimens by Standard EN ISO 6892-1:2016.

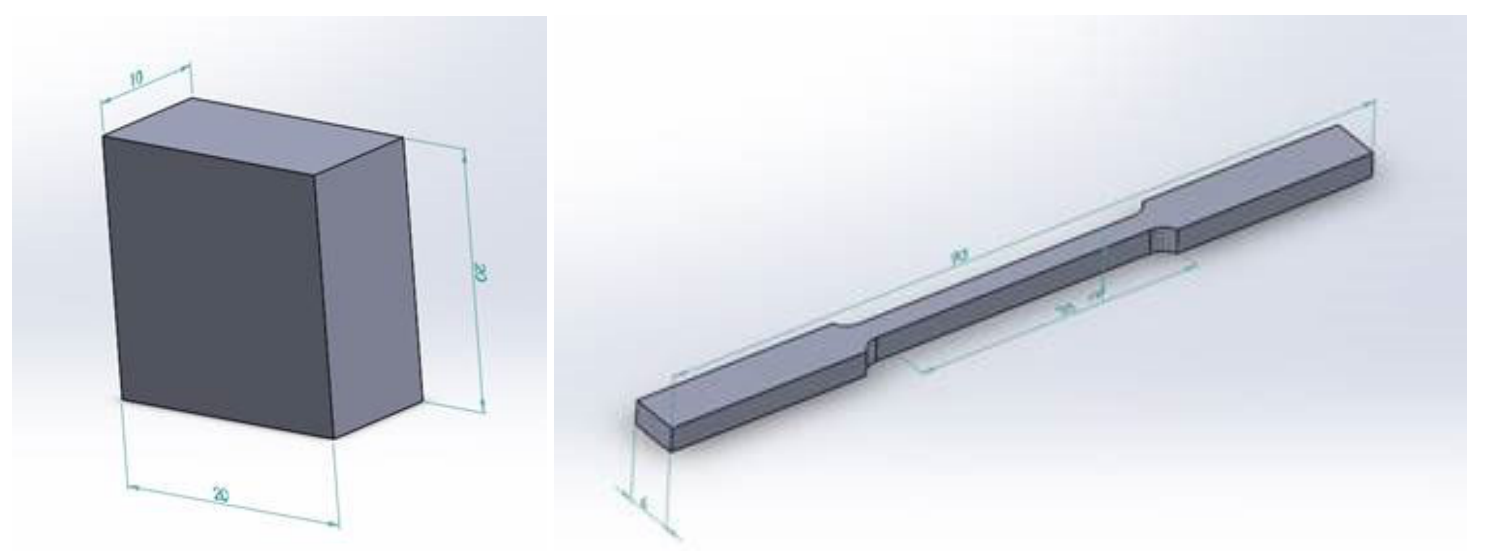

Figure 3. Specimens for microstructure studies (left) and tensile tests (right) 


\section{Mechanical properties and microstructure}

Plate type specimens were produced using different parameters, with laser power and scan speed being chosen as two control factors for the whole printing process. Figure 4 shows mechanical properties of samples, sintered using a constant scan speed of $800 \mathrm{~mm} / \mathrm{s}$ and a laser power range from 70 to $195 \mathrm{~W}$. Six different power values were selected: 70 , $95,120,145,170$ and $195 \mathrm{~W}$. It can be seen in the graph that the values of yield strength and tensile strength increase gradually when the laser power increases. Gradual growth of the Young's modulus is visible as well. Yield strength of the sample part printed with the highest laser power is more than 4 times greater compared to the lowest laser power used in the experiment, tensile strength - more than 4 times as well, Young's modulus - more than 2 times. Another experiment (Figure 5) with a constant laser power of $120 \mathrm{~W}$ and a variable scan speed $(200,400,600,800,1000 \mathrm{~mm} / \mathrm{s})$ shows quite consistent results as well with yield strength decreasing gradually when the scan speed is increased. The yield strength difference between the lowest and highest scan speed applied is approximately 2 times. Tensile strength and Young's modulus tend to decrease when the scan speed increases as well, with the scan speed of $600 \mathrm{~mm} / \mathrm{s}$ being the only exception where tensile strengh is higher $(1029.5 \mathrm{MPa})$ and Young's modulus drops to less than $200 \mathrm{GPa}$. The graph in Figure 6. shows mechanical properties of parts printed using different both scan speed and laser power where the energy density stays the same $\left(61 \mathrm{~W} / \mathrm{mm}^{3}\right)$ throughout the whole experiment. Five different values of laser power were used: 70, 95, 120,145, 170 and $195 \mathrm{~W}$. In order to keep the energy density, the same, different scan speed values were applied: $287,389,492,594,697,800 \mathrm{~mm} / \mathrm{s}$. Gradual growth of all three parameters can be observed with the first column of the graph $(70 \mathrm{~W}$ and $287 \mathrm{~mm} / \mathrm{s}$ ) being the only exception where the values of tensile strength and Young's modulus are relatively high (1009.5 $\mathrm{MPa}$ and $272 \mathrm{GPa})$.

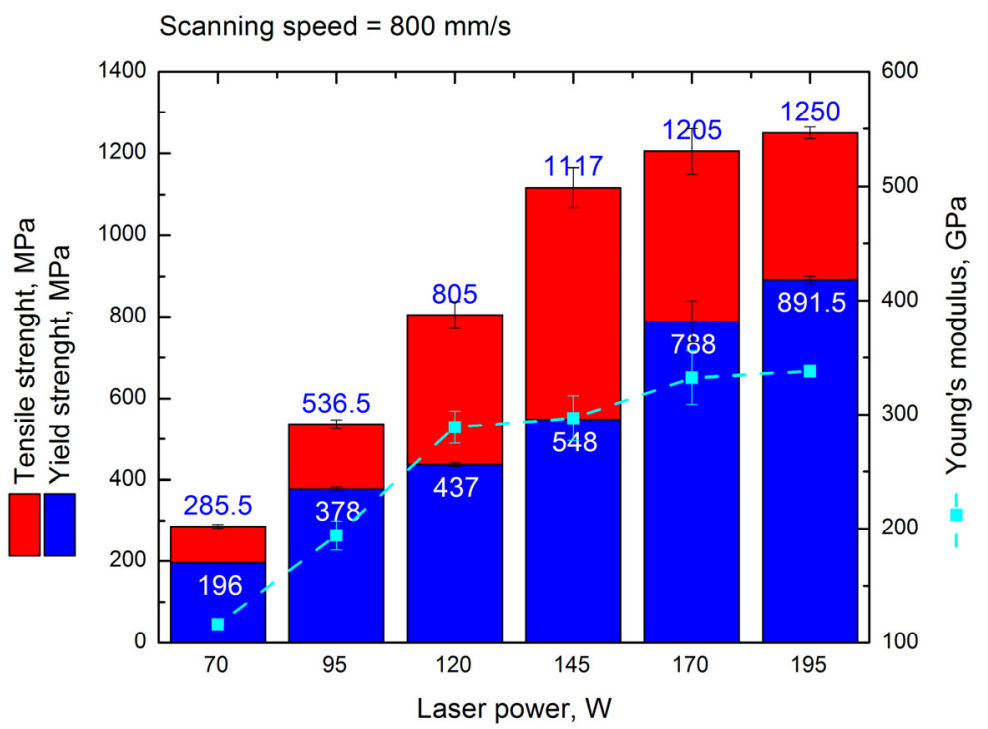

Figure 4. Mechanical properties of specimens produced with a constant scanning speed

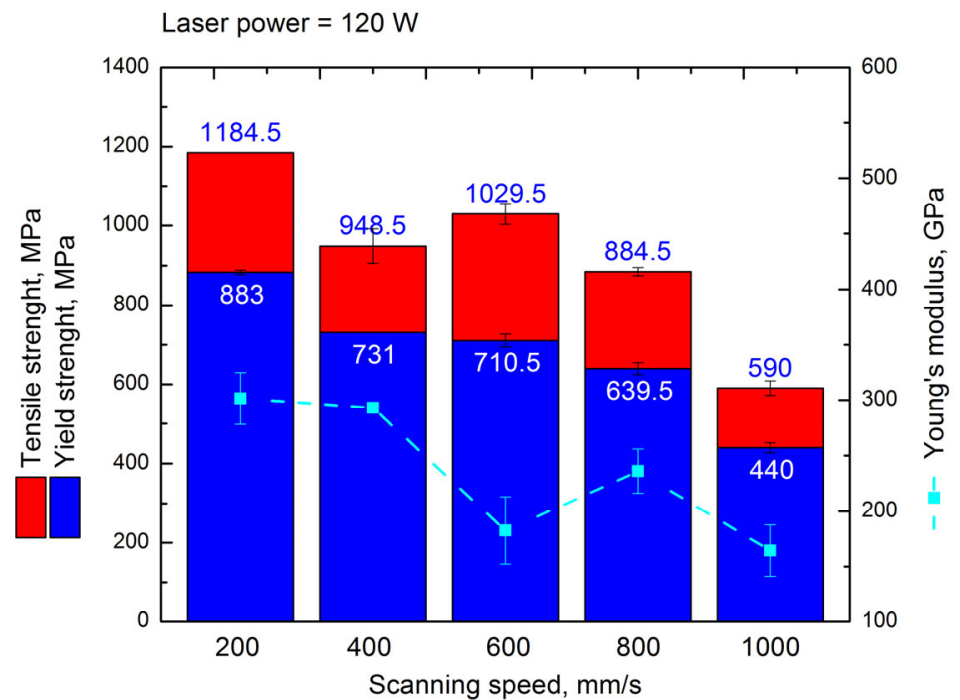

Figure 5. Mechanical properties of specimens produced with a constant laser power 
Mordas, G.; Steponavičiūtè, A.; Selskiene, A.; Tretjakovas, J.; Borodinas, S. 2019.

Direct Metal Laser Sintering of stainless steel alloy: microstructure and mechanical properties

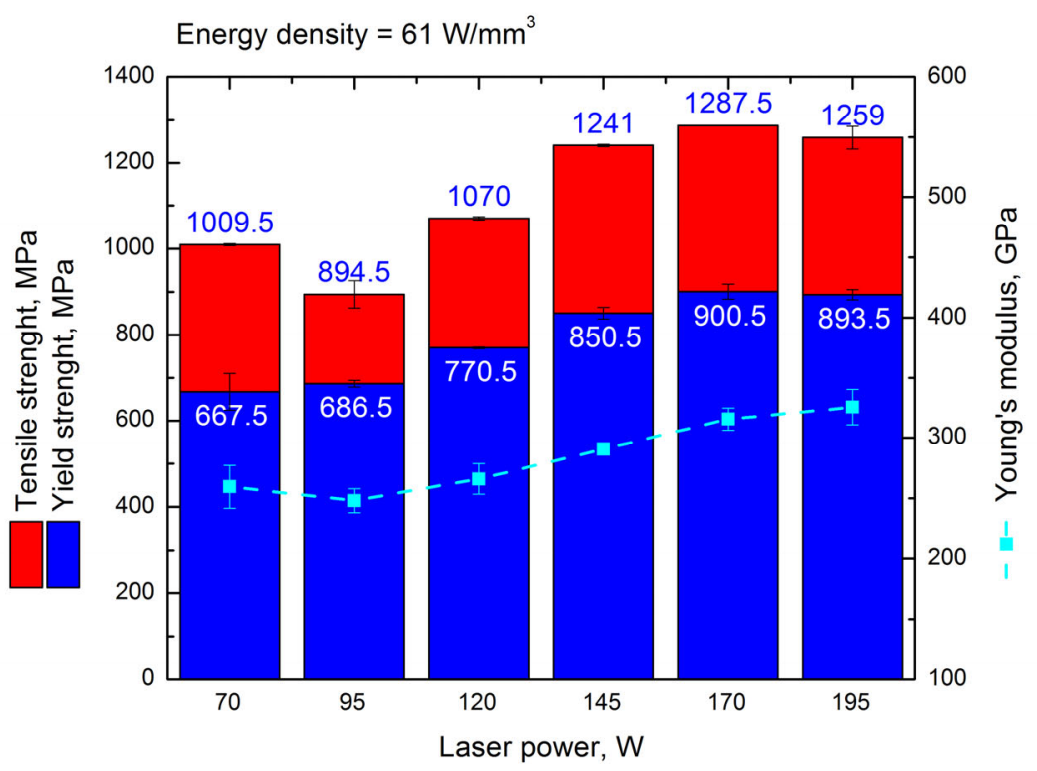

Figure 6. Mechanical properties of specimens produced with a constant energy density

In order to look into the tensile strengh dependence on the laser power (Figure 6), we investigated the microstructure of two samples: with the highest and with the lowest tensile stregth. Figure 7 shows two micrographs - printed with a laser power of $170 \mathrm{~W}$ and a scan speed of $697 \mathrm{~mm} / \mathrm{s}$ on the left (a) and with a laser power of $70 \mathrm{~W}$ and a scan speed of $800 \mathrm{~mm} / \mathrm{s}$ on the right (b). These two specimens have the highest and the lowest tensile strength values of all the specimens which were examined in our study. Figure X. a) shows a cross-section view with a smooth surface, containing only small cracks and pores with a low defect density of approximately 20 pores in an area of $1 \mathrm{~mm}^{2}$, the biggest pores being $40-50 \mu \mathrm{m}$ in diameter. The cross-section of a specimen, printed with a laser power of $70 \mathrm{~W}$ and a scan speed of $800 \mathrm{~mm} / \mathrm{s}$ is shown in Figure X. b). More than $20 \%$ of the surface is covered in defects of various shapes and sizes, cracks and holes with unmolten powder particles inside them can be observed.
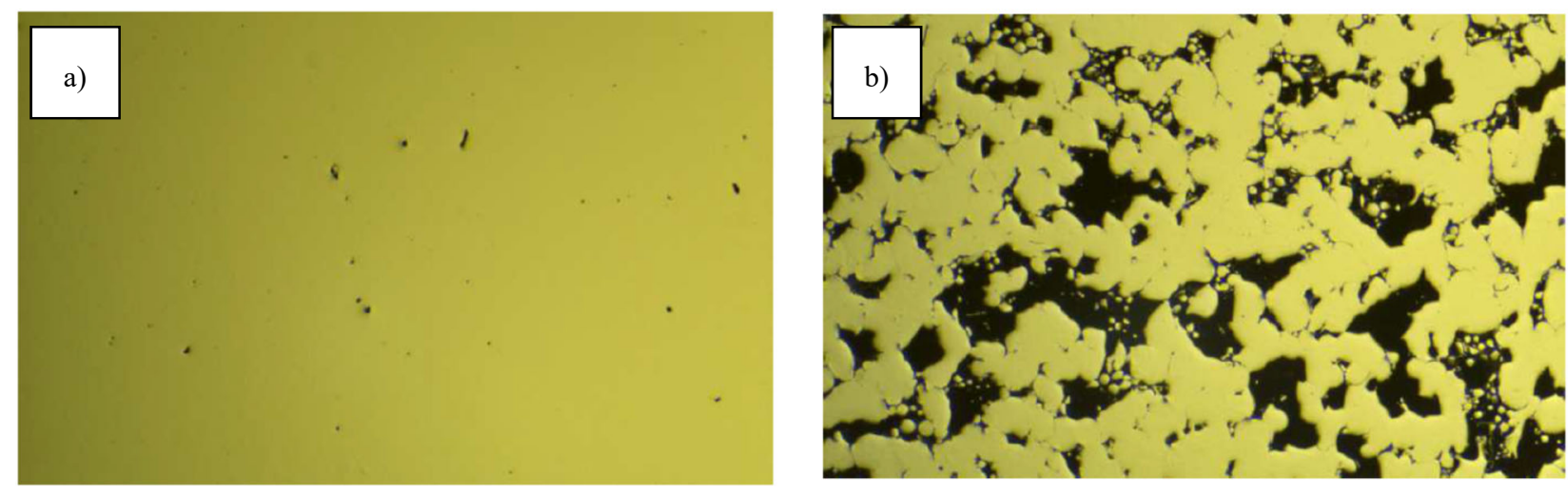

300 um

300 um

Figure 7. Pore morphology and locations on the polished cross sections of the DMLS material:

a) - at optimal DMLS parameters; b) - at worse parameters

\section{Conclusions}

This study focuses on the DMLS technology used in metal additive manufacturing, metal powder investigation and the influence of the $\mathrm{D} \mid \mathrm{MLS}$ process parameters on the mechanical properties and microstructure of additively manufactured parts.

The morphology of the LPW GP1 powder was determined by SEM. The images showed that powder has a polydisperse particle size distribution from 10 to $50 \mu \mathrm{m}$. SEM-EDS analysis provided average chemical composition results of 10 particles and these results showed that chemical element amounts are in the same range as the default chemical composition estimated by the powder manufacturer. 
Specimens for testing were produced using different parameters (constant scan speed, constant laser power and constant energy density) and their effect on mechanical properties was determined. Parts printed with a laser power of $170 \mathrm{~W}$ and scan speed of $697 \mathrm{~mm} / \mathrm{s}$ had the highest values of ultimate and yield strengths of all the specimens that were produced in this study.

The same specimen $(170 \mathrm{~W}, 697 \mathrm{~mm} / \mathrm{s})$ resulted in the best microstructure. A vertical cross-section with a polished surface revealed very few defects while a specimen printed with a $70 \mathrm{~W}$ laser power and a scan speed of $287 \mathrm{~mm} / \mathrm{s}$ had its surface covered in defects of various shapes and sizes, some of them containing unmolten powder particles inside.

\section{References}

Abe, F., Osakada, K., Shiomi, M., Uematsu, K., \& Matsumoto, M. (2001). The manufacturing of hard tools from metallic powders by selective laser melting. Journal of Materials Processing Technology, 111, 210-213. https://doi.org/10.1016/S0924-0136(01)00522-2

Aboulkhair, N. T., Maskery, I., Tuck, C., Ashcroft, I., \& Everitt, N. M. (2016). Improving the fatigue behaviour of a selectively laser melted aluminium alloy: Influence of heat treatment and surface quality. Materials \& Design, 104, 174-182. https://doi.org/10.1016/j.matdes.2016.05.041

EOS GmbH. (2001). EOS takes fine approach to laser sintering. Metal Powder Report, 56(3), 18. https://doi.org/10.1016/S0026-0657(01)80108-9

Hanninen, J. (2002). Direct metal laser sintering. Advanced Materials and Processes, 160, 33-36.

LPW GP1 specifications. (2017). Retrieved from https:/carpenteradditive.com/wp-content/uploads/2016/11/LPW-Powders-Brochure-2017.pdf

Pham, D. T., \& Dimov, S. S. (2001). Rapid manufacturing: the technologies and applications of rapid prototyping and rapid tooling. London: Springer-Verlag. https://doi.org/10.1007/978-1-4471-0703-3

Samal, P. K., \& Newkirk, J. W. (Eds). (2015). ASM handbook powder metallurgy (vol. 7). ASM International Materials Park, Ohio.

Sanz, C., \& Navas, V. G. (2013). Structural integrity of direct metal laser sintered parts subjected to thermal and finishing treatments. Journal of Materials Processing Technology, 213(12), 2126-2136. https://doi.org/10.1016/j.jmatprotec.2013.06.013

Viramgama, M. D., \& Karia, M. C. (2016). Study and investigation of influence of process parameters for selective laser melting. International Journal of Engineering Development and Research, 4(1), 578-585. 